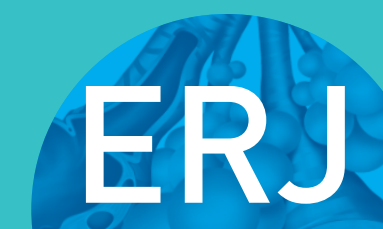

open research
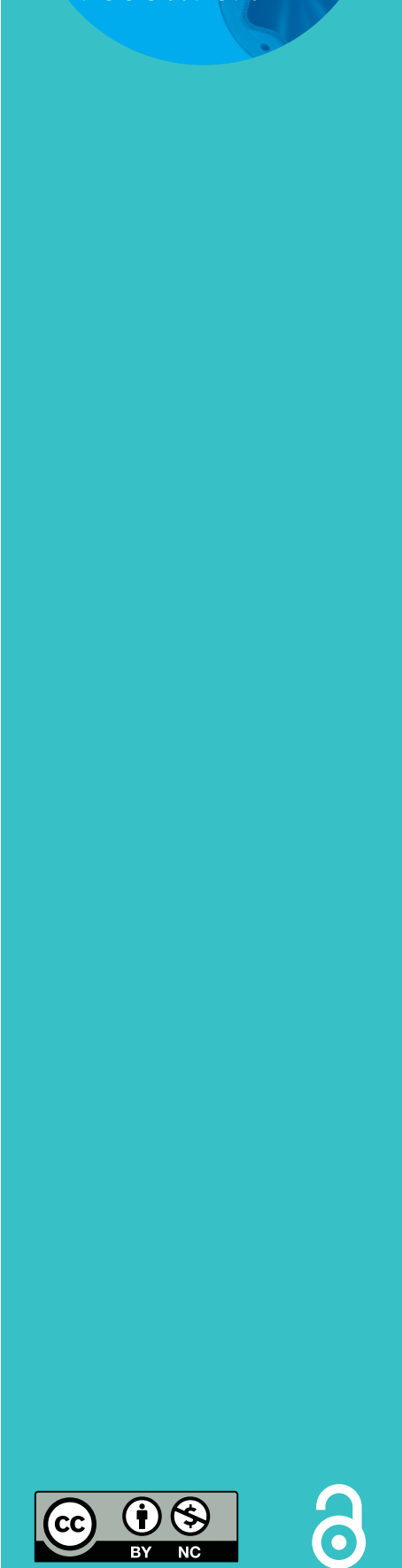

\section{New anti-tuberculosis drugs and regimens: 2015 update}

\author{
Lia D’Ambrosio ${ }^{1,6}$, Rosella Centis ${ }^{1,6}$, Giovanni Sotgiu², Emanuele Pontali ${ }^{3}$, \\ Antonio Spanevello ${ }^{4,5}$ and Giovanni Battista Migliori ${ }^{1}$
}

Affiliations: ${ }^{1}$ WHO Collaborating Centre for Tuberculosis \& Lung Diseases, Fondazione S. Maugeri, IRCCS, Tradate, Italy. ${ }^{2}$ Clinical Epidemiology and Medical Statistics Unit, Department of Biomedical Sciences, University of Sassari - Research, Medical Education and Professional Development Unit, AOU Sassari, Sassari, Italy. ${ }^{3}$ Department of Infectious Diseases, Galliera Hospital, Genoa, Italy. ${ }^{4}$ Pneumology Unit, Fondazione Maugeri, IRCCS, Tradate, Italy. ${ }^{5}$ Dept of Clinical and Experimental Medicine, University of Insubria, Varese, Italy. ${ }^{6}$ These authors contributed equally.

Correspondence: Giovanni Battista Migliori, World Health Organization Collaborating Centre for Tuberculosis and Lung Diseases, Fondazione S. Maugeri, IRCCS, Via Roncaccio 16, 21049, Tradate, Italy.

E-mail: giovannibattista.miglioriafsm.it

ABSTRACT Over 480000 cases of multidrug-resistant (MDR) tuberculosis (TB) occur every year globally, $9 \%$ of them being affected by extensively drug-resistant (XDR) strains of Mycobacterium tuberculosis. The treatment of MDR/XDR-TB is unfortunately long, toxic and expensive, and the success rate largely unsatisfactory ( $<20 \%$ among cases with resistance patterns beyond XDR).

The aim of this review is to summarise the available evidence-based updated international recommendations to manage $\mathrm{MDR} / \mathrm{XDR}-\mathrm{TB}$, and to update the reader on the role of newly developed drugs (delamanid, bedaquiline and pretomanid) as well as repurposed drugs (linezolid and meropenem clavulanate, among others) used to treat these conditions within new regimens.

A nonsystematic review based on historical trials results as well as on recent literature and World Health Organization (WHO) guidelines has been performed, with special focus on the approach to managing MDR/XDR-TB.

The new, innovative global public health interventions, recently approved by WHO and known as the "End TB Strategy", support the vision of a TB-free world with zero death, disease and suffering due to TB. Adequate, universally accessed treatment is a pre-requisite to reach TB elimination. New shorter, cheap, safe and effective anti-TB regimens are necessary to boost TB elimination.

@ERSpublications

The new WHO post-2015 End TB Strategy will support the efforts that research on new drugs and regimens requires http://ow.ly/LnJER

Received: April 12015 | Accepted: April 32015

Conflict of interest: None declared.

The content of this work is @ the authors or their employers. Design and branding are @ERS 2015. This article is open access and distributed under the terms of the Creative Commons Attribution Non-Commercial Licence 4.0 


\section{Introduction}

In 2014, the World Health Organization (WHO) estimated 9 million new tuberculosis (TB) cases had occurred globally in 2013, 480000 of them being affected by multidrug-resistant (MDR) Mycobacterium tuberculosis strains [1]. MDR-TB is defined as resistance in vitro to at least isoniazid and rifampicin, while extensively drug-resistant (XDR)-TB is resistant to at least one fluoroquinolone and one injectable second-line anti-TB drug in addition to isoniazid and rifampicin [2-5].

In "hot spots" (e.g. in some former Soviet Union countries), between $20 \%$ and $30 \%$ of the new TB cases are infected by MDR-TB strains (the global average is 3.5\%) [1], while a proportion up to $50 \%$ is observed among retreated cases (figs 1 and 2) [3, 6, 7]. As MDR/XDR-TB clinical outcomes are largely suboptimal and their treatment very long, toxic and expensive, these difficult-to-treat cases are considered a serious threat to TB control and elimination $[4,5,8,9]$.

A recent study demonstrated that while in Germany the MDR-TB treatment-related costs exceed $€ 50000$ [8], in Europe, the average cost to treat a single XDR-TB case is over $€ 160000$ [8]. The largest meta-analytic study presently available revealed that MDR-TB treatment success is only $54 \%$ (with $15 \%$ death, $8 \%$ failure/relapse and 23\% default). When the drug resistance profile is beyond XDR (with increasing complexity), the outcomes are unfortunately lower: treatment success ranges from $40 \%$ to $19 \%$, failure/relapse from $15 \%$ to $54 \%$ and death from $15 \%$ to $35 \%[4,5]$.

Every day, clinicians managing these cases face relevant challenges that include frequent occurrence of adverse events, problems in patients' adherence, lack of clinical experience, and limited availability of adequate diagnostics and second-line anti-TB drugs (in some countries). The risk of acquiring further drug resistance is therefore real.

WHO has recently launched its innovative "End TB Strategy" [1], supporting the TB elimination strategy and the vision of a TB-free world with zero death, disease and suffering due to TB [10-12]. The new strategy clearly supports universal access to high-quality MDR-TB diagnosis and treatment. However, since the market launch of rifampicin in the early 1960s, no new anti-TB drug has been specifically developed until recently, while significant progress has been achieved in the area of diagnostics (e.g. Xpert MTB/RIF test; Cepheid, Sunnyvale, CA, USA) [1,13]. The need for new drugs and regimens is obvious [14-16].

The aim of this review is to summarise, based on evidence, how to design an anti-TB regimen, and the updated international recommendations to manage MDR/XDR-TB, and to update the reader on the role of newly developed drugs (delamanid, bedaquiline and pretomanid) as well as repurposed drugs (linezolid and meropenem clavulanate, among others) used to treat these conditions within new regimens. A nonsystematic review based on historical trials results as well as on recent literature and WHO guidelines has been performed, with special focus on the approach to managing MDR/XDR-TB.

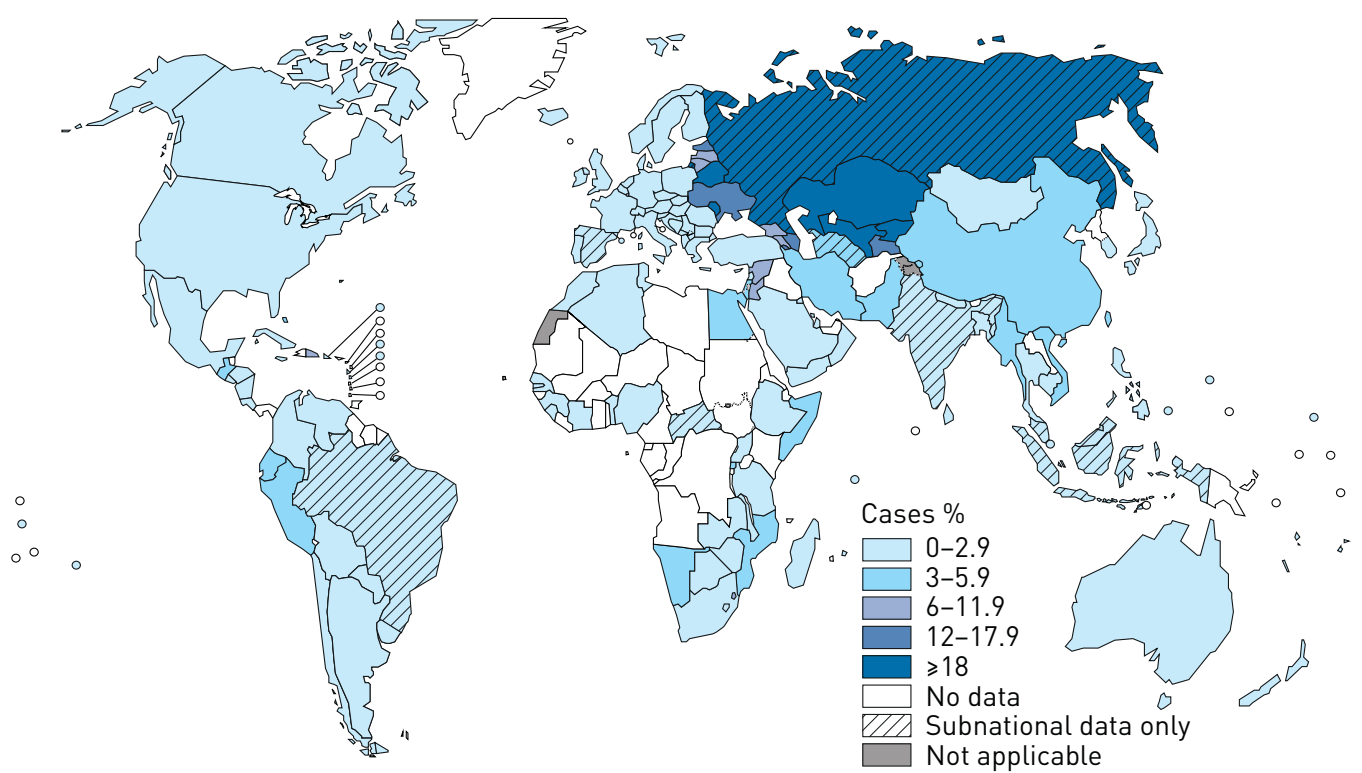

FIGURE 1 Percentage of new tuberculosis (TB) cases with multidrug-resistant TB. Figures are based on the most recent year for which data have been reported, which varies among countries. Reproduced from [1] with permission from the publisher. 


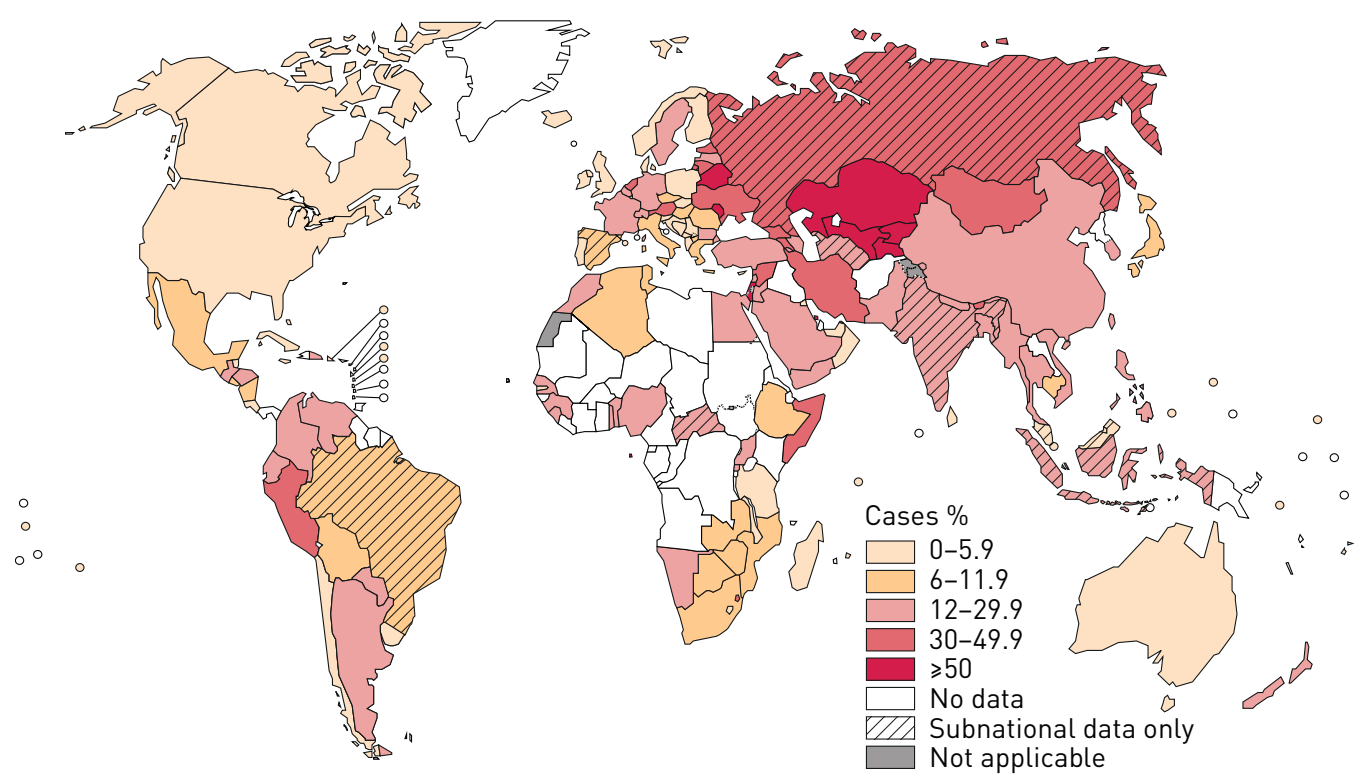

FIGURE 2 Percentage of previously treated tuberculosis (TB) cases with multidrug-resistant (MDR)-TB. Figures are based on the most recent year for which data have been resported, which varies among countries. The high percentages of previously treated TB cases with MDR-TB in Bahrain, Bonaire, Israel, Saint Eustatius and Saba, and Sao Tomé and Principe refer to only small numbers of notified cases (range 1-8 notified previously treated TB cases). Reproduced from [1] with permission from the publisher.

\section{Designing a regimen to treat $\mathrm{TB}$}

The treatment regimens, approved TB drugs and the dosage of anti-TB drugs recommended by the evidence-based WHO guidelines (presently under revision) are summarised in tables 1 and 2. "New" and "retreatment" cases are clearly separated, 30 days of previous anti-TB treatment being the cut-off [17]. New TB cases (irrespective of HIV status) should be treated for the first 2 months (intensive phase) with isoniazid, rifampicin, pyrazinamide and ethambutol, followed by isoniazid and rifampicin for the remaining 4 months (continuation phase) [17]. The daily dosage is recommended (although the three times weekly dosing can be used during the continuation phase under directly observed therapy) as well as the fixed-dose combinations [18].

Drug susceptibility testing (DST) (rapid and/or conventional) is strongly recommended by WHO in all cases and particularly for those previously treated [1]. While awaiting DST results, in settings with a

\section{TABLE 1 World Health Organization recommended treatment regimens for new patients}

\begin{tabular}{|c|c|c|c|}
\hline \multicolumn{2}{|c|}{ Intensive phase } & \multicolumn{2}{|c|}{ Continuation phase } \\
\hline Drug & Duration months & Drug & Duration months \\
\hline $\begin{array}{l}\text { Ethambutol }^{\#} \\
\text { Isoniazid } \\
\text { Pyrazinamide } \\
\text { Rifampicin }\end{array}$ & 2 & $\begin{array}{l}\text { Isoniazid? } \\
\text { Rifampicin }\end{array}$ & 4 \\
\hline $\begin{array}{l}\text { Ethambutol }{ }^{\#} \\
\text { Isoniazid } \\
\text { Pyrazinamide } \\
\text { Rifampicin }\end{array}$ & 2 & $\begin{array}{l}\text { Ethambutol } \\
\text { Isoniazid" } \\
\text { Rifampicin" }\end{array}$ & $4^{+}$ \\
\hline \multicolumn{4}{|c|}{$\begin{array}{l}\text { \# : ethambutol has to be prescribed in individuals with noncavitary, sputum smear-negative pulmonary } \\
\text { tuberculosis (TB) or with extrapulmonary TB who are known to be HIV negative; in TB meningitis, it should } \\
\text { be replaced by streptomycin. ?: the World Health Organization considers the three times per week } \\
\text { continuation phase as an acceptable alternative for any new TB patient receiving directly observed therapy. } \\
{ }^{+} \text {: when the level of isoniazid resistance among new cases is elevated and in vitro isoniazid drug } \\
\text { susceptibility testing is not available, isoniazid (H)-rifampicin (R)-ethambutol regimen may be an } \\
\text { acceptable alternative to HR regimen. Information from [17]. }\end{array}$} \\
\hline
\end{tabular}


TABLE 2 World Health Organization recommended treatment regimens for previously treated patients, pending drug susceptibility testing (DST) results ${ }^{\#}$

\begin{tabular}{|c|c|c|}
\hline \multicolumn{3}{|c|}{ Probability of MDR-TB } \\
\hline \multicolumn{2}{|c|}{ Medium or low" } & \multirow[t]{2}{*}{$\mathrm{High}^{+}$} \\
\hline Drug & Duration months (phase) & \\
\hline $\begin{array}{l}\text { Ethambutol } \\
\text { Isoniazid } \\
\text { Pyrazinamide } \\
\text { Rifampicin } \\
\text { Streptomycin }\end{array}$ & 2 (intensive) & Empirical MDR-TB regimen \\
\hline $\begin{array}{l}\text { Ethambutol } \\
\text { Isoniazid } \\
\text { Pyrazinamide } \\
\text { Rifampicin } \\
\text { Ethambutol } \\
\text { Isoniazid } \\
\text { Rifampicin }\end{array}$ & 1 (intensive) & \\
\hline $\begin{array}{l}\text { To be changed once DST testing } \\
\text { results are available }\end{array}$ & 5 (continuation) & $\begin{array}{l}\text { To be changed once DST } \\
\text { testing results are available }\end{array}$ \\
\hline $\begin{array}{l}\text { MDR: multidrug-resistant; TB: } \\
\text { lost to follow-up; }{ }^{+} \text {: failure. Info }\end{array}$ & $\begin{array}{l}\text { s. \#: up to } 2-3 \text { months af } \\
\text { m [17]. }\end{array}$ & cart of treatment; ๆ: relapse, \\
\hline
\end{tabular}

medium or low probability of MDR-TB, retreatment cases could initially be treated with an empiric regimen including isoniazid, rifampicin, pyrazinamide, ethambutol and streptomycin for 2 months, followed by isoniazid, rifampicin, pyrazinamide and ethambutol for 1 month, and isoniazid, rifampicin, and ethambutol for 5 months.

\section{Designing a regimen to treat MDR-TB}

Based on their effectiveness and safety, WHO identified five groups of anti-TB drugs (table 3) [9]. A stepwise approach is recommended to design treatment regimens for MDR-TB cases (table 4) [9, 19, 20]. Although DST-guided individualised regimens have to be preferred, standardised regimens are used in setting where DST is not available. They are based on representative patient population data, ensuring that treatment regimens are likely to include a sufficient number of active drugs (four) to ensure treatment success.

Rational MDR-TB treatment should include a minimum of four active drugs: a later-generation fluoroquinolone (moxifloxacin, gatifloxacin or levofloxacin) plus an injectable aminoglycoside (amikacin, capreomycin or kanamycin) plus any first-line drug to which the isolate is susceptible (e.g., pyrazinamide) plus the addition of one drug from group 4 (cycloserine, p-aminosalicylic acid (PAS), terizidone, prothionamide or ethionamide) (table 4). The drugs belonging to group 5 should be included whenever four active drugs are not available from previous groups. When using injectables, the minimum duration of the intensive phase is 8 months, the continuation phase lasting for $12-18$ months, for a total treatment duration of at least 20 months. As a rule, 18 months need to be added to the date of the first negative culture to define the final treatment duration. In the case of failure to achieve culture conversion, the underlying causes (incorrect drug dosage, quality of drug supply, nonadherence factors, malabsorption and comorbidity) need to be identified and, possibly, corrected.

Unfortunately, the TB armamentarium is presently based on a limited number of effective drugs and the "optimised background regimens" (OBRs) used in clinical practice have not been tested in randomised controlled trials: clinicians are often forced to add some toxic old drugs (e.g. PAS, ethionamide and cycloserine) to more effective drugs that have been developed for indications other than TB.

\section{Repurposed drugs}

Linezolid

Linezolid was prescribed "off label" before reliable data from multicentre observational studies were made available [21]. At a later stage, systematic (individual and nonindividual) reviews and experimental data further defined the linezolid profile [22-27]. 


\section{TABLE 3 World Health Organization groups of first- and second-line anti-TB drugs}

\section{Group}

1) First-line oral anti-TB drugs

2) Injectable anti-TB drugs (injectable or parenteral agents)

3) Fluoroquinolones (FQs)

\section{4) Oral bacteriostatic second-line anti-TB drugs}

5) Anti-TB drugs with limited data on efficacy and/or long-term safety in the treatment of drug-resistant TB
Anti-TB drugs

Isoniazid $(\mathrm{H})$

Rifampicin (R)

Ethambutol (E)

Pyrazinamide (Z)

Rifabutin (Rfb)

Rifapentine (Rpt)

Streptomycin (S)

Kanamycin $(\mathrm{Km})$

Amikacin (Am)

Capreomycin $(\mathrm{Cm})$

Levofloxacin (Lfx)

Moxifloxacin (Mfx)

Gatifloxacin (Gfx)

Ofloxacin (Ofx)

Ethionamide (Eto)

Prothionamide (Pto)

Cycloserine (Cs)

Terizidone (Trd)

p-Aminosalicylic acid (PAS)

p-Aminosalicylate sodium (PAS-Na)

Bedaquiline (Bdq)

Delamanid (DIm)

Linezolid (Lzd)

Clofazimine (Cfz)

Amoxicillin/clavulanate (Amx/Clv)

Imipenem/cilastatin (Ipm/Cln) Meropenem (Mpm)

High-dose isoniazid (high-dose $\mathrm{H}$ )

Thioacetazone (T)

Clarithromycin (Clr)

TB: tuberculosis. Reproduced and modified from [19] with permission from the publisher.

Linezolid, a first-generation oxazolidinone, demonstrated clinical effectiveness in most difficult-to-treat drug-resistant cases, although the frequency and severity of adverse events (i.e. peripheral neuropathy, optic neuropathy, gastrointestinal disorders and myelosuppression) limit its long-term use [23]. A recent prospective randomised trial enrolling XDR-TB patients failing previous chemotherapy demonstrated the efficacy of a reduced linezolid dosage (300-600 mg per day), confirming previous findings [21]: $87 \%$ of all enrolled patients achieved bacteriological conversion within 6 months [24]. As four patients acquired resistance during treatment (three of them receiving $300 \mathrm{mg}$ per day), additional evidence is necessary to assess the optimal dose and adequate duration of treatment. Interesting studies have been conducted to prevent adverse events while maintaining the efficacy of linezolid using intermittent dosing and of increasing linezolid concentration in combination with clarithromycin (table 5) [28, 29]. An innovative study from the Netherlands [29] suggested that clarithromycin can boost the blood levels of linezolid, allowing administration of lower doses with fewer adverse events and economic savings. A recent individual-data meta-analysis [23] provided updated evidence on efficacy, safety and tolerability of linezolid, and indirect evidence that a proper treatment drug monitoring (TDM)) approach to drug dosage can reduce linezolid toxicity (fig. 3) [31].

Recently, although not yet approved by regulatory authorities, another oxazolidinone drug (sutezolid) is attracting interest, being better tolerated [32].

As of today, a daily linezolid dose ranging between 300 and $600 \mathrm{mg}$ seems to be adequate to treat MDR/ XDR-TB when added to OBR [21-29, 31-35].

\section{Meropenem/clavulanate}

Meropenem clavulanate is active in vitro against $M$. tuberculosis, showing a good tolerability profile. Meropenem and clavulanate together have a potent in vitro activity against $M$. tuberculosis, as clavulanate 


\section{TABLE 4 World Health Organization recommended treatment regimen for multidrug-resistant} (MDR) tuberculosis (TB)

1 Chose an injectable (group 2)

Kanamycin

Amikacin

Capreomycin

2 Choose a higher-generation fluoroquinolone (group 3)

3 Add group 4 drugs

4 Add group 1 drugs

5 Add group 5 drugs
Levofloxacin

Moxifloxacin

Cycloserine/

terizidone

PAS

Ethionamide/

prothionamide

Pyrazinamide

Ethambutol

Bedaquiline
Linezolid
Clofazimine
Amoxicillin/
clavulanate
Imipenem/cilastatin
plus clavulanate
Meropenem plus
clavulanate
High-dose isoniazid
Clarithromycin
Thioacetazone

Bedaquiline

inezolid

Amoxicillin/

clavulanate

plus clavulanate

plus

High-dose isoniazid

Thioacetazone
Choose a drug based on DST and treatment history

Streptomycin is generally not used because of high rates of resistance in patients with MDR-TB

Use a later-generation fluoroquinolone

If levofloxacin (or ofloxacin) resistance is documented, use moxifloxacin

Avoid moxifloxacin if possible when using bedaquiline

Add two or more group 4 drugs until there are at least four second-line anti-TB drugs likely to be effective

Ethionamide/prothionamide is considered the most effective group 4 drug

Consider treatment history, side-effect profile and cost

DST is not considered reliable for the drugs in this group

Pyrazinamide is routinely added in most regimens

Ethambutol can be added in the case of full sensitivity

If isoniazid DST is unknown or pending it, can be added to the regimen until DST results become available

Consider adding group 5 drugs if four second-line anti-TB drugs are not likely to be effective from groups $2-4$

If drugs are needed from this group, it is recommended to add two or more

DST is not standardised for the drugs in this group

DST: drug susceptibility testing; PAS: p-aminosalicylic acid. Information from [19].

inhibits the extended-spectrum $\beta$-lactamase $(\mathrm{BlaC})$ produced by $\mathrm{TB}$ bacilli, which generally hamper the activity of $\beta$-lactam antibiotics like meropenem. In a recently published case-control study, meropenem/ clavulanate added to an OBR regimen containing linezolid (at the dose of $1 \mathrm{~g}$ three times a day) achieved high smear and culture conversion in MDR/XDR-TB (table 5) [30]. Further studies are presently ongoing to define the role of meropenem/clavulanate within the group 5 drugs.

\section{Other drugs}

Anecdotal reports suggest that other repurposed drugs, including sulfamethoxazole and mefloquine, showed activity against M. tuberculosis in difficult-to-treat cases, although high-quality evidence, based on randomised clinical trials, is necessary [37-38].

\section{New drugs}

Currently, as a result of a multi-stakeholder initiative, two new anti-TB drugs were approved by the US Food and Drug Administration and by the European Medicines Agency: bedaquiline and delamanid [39, 40]. In addition, pretomanid, sutezolid (mentioned earlier), SQ109 and benzothiazinones will be discussed.

\section{Bedaquiline}

Bedaquiline, belonging to the diarylquinoline class of antibiotics (table 6), selectively targets the proton pump of ATP synthesis, leading to inadequate ATP synthesis, which is necessary for bacterial metabolism 
TABLE 5 Summary of the main repurposed antituberculosis drugs with the most relevant studies and related findings

\begin{tabular}{lll} 
Drug & Class & Main findings \\
\hline Linezolid & Oxazolidinone & Systematic review and meta-analysis of efficacy, safety and tolerability of linezolid-containing
\end{tabular}
regimes based on individual data analysis of 12 studies (11 countries from three continents) reporting complete information on safety, tolerability, efficacy of linezolid-containing regimes in treating MDR-TB cases. Most MDR-TB cases achieved SS (86 (92.5\%) out of 93) and C (100 $(93.5 \%)$ out of 107$)$ conversion after treatment with individualised regimens containing linezolid (median (interquartile range) times for SS and C conversions were 43.5 (21-90) and 61 (29-119) days, respectively) and $99(81.8 \%)$ out of 121 patients were successfully treated. No significant differences were detected in the subgroup efficacy analysis (daily linezolid dosage $\leq 600$ versus $>600 \mathrm{mg}$ ). AEs were observed in $63(58.9 \%)$ out of 107 patients, of which $54(68.4 \%)$ out of 79 were major AEs that included anaemia (38.1\%), peripheral neuropathy (47.1\%), gastrointestinal disorders $(16.7 \%)$ optic neuritis $(13.2 \%)$ and thrombocytopenia $(11.8 \%)$. The proportion of adverse events was significantly higher when the linezolid daily dosage exceeded $600 \mathrm{mg}$. The study results suggest an excellent efficacy but also the necessity for caution in the prescription of linezolid.

Retrospective, nonrandomised, unblinded observational study evaluating safety and tolerability of linezolid $(600 \mathrm{mg}$ once or twice daily). In MDR/XDR-TB treatment in four European countries. Out of $195 \mathrm{MDR} / \mathrm{XDR}$-TB patients, 85 were treated with linezolid for a mean of 221 days. Of these, $35(41.2 \%)$ out of 85 experienced major AEs attributed to linezolid (anaemia, thrombocytopenia and/or polyneuropathy), requiring discontinuation in $27(77 \%)$ cases. Most AEs occurred after 60 days of treatment. Twice-daily administration produced more major AEs than once-daily dosing $(p=0.0004)$, with no difference in efficacy found. Outcomes were similar in patients treated with/without linezolid ( $p=0.8)$, although linezolid-treated cases had more first-line ( $p=0.002)$ and second-line $(p=0.02)$ drug resistance and a higher number of previous treatment regimens ( 4.5 versus $2.3 ; p=0.07$ ). Linezolid $600 \mathrm{mg}$ once daily added to an individualised multidrug regimen may improve the chance of bacteriological conversion, providing a better chance of treatment success in only the most complicated MDR/XDR-TB cases. Its safety profile does not warrant use in cases for which there are other, safer, alternatives.

41 patients were enrolled, who had C-positive XDR-TB and who had not had a response to any available chemotherapeutic option during the previous 6 months. Patients were randomly assigned to linezolid therapy that started immediately or after 2 months, at a dose of $600 \mathrm{mg}$ per day, without a change in their OBR. The primary end-point was the time to SS/C conversion on solid medium, with data censored 4 months after study entry. By 4 months, 15 (79\%) out of 19 patients in the immediate-start group and seven (35\%) out of 20 in the delayed-start group had $\mathrm{C}$ conversion $(\mathrm{p}=0.001)$. $34(87 \%)$ out of 39 patients had a negative $\mathrm{C}$ within 6 months after linezolid had been added to their drug regimen. Of the 38 patients with exposure to linezolid, $31(82 \%)$ had clinically significant AEs that were possibly or probably related to linezolid, including three patients who discontinued therapy. Patients who received $300 \mathrm{mg}$ per day after the second randomisation had fewer AEs than those who continued taking $600 \mathrm{mg}$ per day. 13 patients completed therapy and did not relapse. Four cases of acquired resistance to linezolid were observed. Linezolid is effective at achieving $C$ conversion among patients with treatment-refractory pulmonary XDR-TB but patients must be monitored carefully for AEs.

The authors evaluated treatment with linezolid $1800 \mathrm{mg}$ once daily for 1-4 months as guided by $\mathrm{SS} / \mathrm{C}$ status and tolerance, and then at $1200 \mathrm{mg}$ thrice weekly until $\geq 1$ year after $\mathrm{C}$ conversion) in addition to OBD among 10 consecutive patients with XDR-TB or fluoroquinolone-resistant MDR-TB. All achieved stable cure, with anaemia corrected and neuropathy stabilised, ameliorated, or avoided after switching to intermittent dosing. Serum linezolid profiles appeared better optimised.

Prospective pharmacokinetic study aimed at quantifying the effect of clarithromycin on the exposure of linezolid. All subjects received $300 \mathrm{mg}$ linezolid twice daily during the entire study, consecutively co-administered with 250 and $500 \mathrm{mg}$ clarithromycin once daily. Linezolid exposure increased by a median (interquartile range) of $44 \%$ (23-102\%, $p=0.043$ ) after co-administration of $500 \mathrm{mg}$ clarithromycin ( $n=5)$ compared to baseline, whereas $250 \mathrm{mg}$ clarithromycin had no statistically significant effect. Co-administration was well tolerated by most patients; none experienced severe AEs. One patient reported common toxicity criteria grade 2 gastrointestinal AE. Clarithromycin significantly increased linezolid serum exposure after combining clarithromycin with linezolid in MDR-TB patients. The drugdrug interaction is possibly P-glycoprotein-mediated. Due to large interpatient variability, TDM is advisable to determine individual effect size. 
TABLE 5 Continued

\begin{tabular}{|c|c|c|c|}
\hline Drug & Class & Main findings & [Ref.] \\
\hline $\begin{array}{l}\text { Meropenem/ } \\
\text { clavulanate }\end{array}$ & $\begin{array}{l}\text { Carbapenem/ } \\
\text { clavulanic acid }\end{array}$ & $\begin{array}{l}\text { The study aimed to evaluate the contribution of meropenem/clavulanate when added to } \\
\text { linezolid-containing regimens in terms of efficacy and safety/tolerability in treating MDR/ } \\
\text { XDR-TB cases after } 3 \text { months of second-line treatment. The clinical severity of cases was } \\
\text { worse than that of controls (drug susceptibility profile, proportion of SS positive and of } \\
\text { re-treatment cases). The group of cases yielded a higher proportion of SS converters ( } 28 \\
\text { (87.5\%) out of } 32 \text { versus nine ( } 56.3 \% \text { ) out of } 16 ; p=0.02 \text { ) and C converters }(31(83.8 \%) \text { out of } \\
37 \text { versus } 15(62.5 \% \text { ) out of } 24 ; p=0.06) \text {. Excluding XDR-TB patients (11 (11.2\%) out of } 98 \text { ), } \\
\text { cases scored a significantly higher proportion of C converters than controls ( } p=0.03 \text { ). One } \\
\text { case had to withdraw from meropenem/clavulanate due to increased transaminase levels. } \\
\text { The results of our study provide: } 1 \text { ) preliminary evidence on effectiveness and safety/ } \\
\text { tolerability of meropenem-clavulanate; } 2 \text { ) reference to design further trials; and } 3 \text { ) a guide to } \\
\text { clinicians for its rationale use within salvage/compassionate regimens. }\end{array}$ & [30] \\
\hline
\end{tabular}

MDR: multidrug-resistant; TB: tuberculosis; SS: sputum smear; C: culture; AE: adverse event; XDR: extensively drug-resistant; OBR: optimised background regimen; SS/C: sputum smear and culture; TDM: therapeutic drug monitoring.

[50]. The minimal inhibitory concentration (MIC) of bedaquiline against M. tuberculosis is very low, and its bactericidal activity in the murine model is superior to that of that of isoniazid and rifampicin [50]. The results of two trials (phase II) suggested that a standard 2-month treatment regimen with bedaquiline yielded high culture conversion rates, rapid sputum culture conversion and low acquired resistance to companion drugs in newly diagnosed MDR-TB cases $[41,51]$.

Based on the available evidence, both WHO and the US Centers for Disease Control and Prevention recently issued recommendations that support the use of bedaquiline, at a dose of $400 \mathrm{mg}$ daily for 2 weeks, then $200 \mathrm{mg}$ three times a week for 22 weeks, added to OBR (as per WHO recommendations) to treat MDR-TB in adults when the following conditions are met: pharmacovigilance is in place, informed consent is ensured and QT monitoring is possible $[52,53]$. As safety concerns for this drug remain because of an increased risk of death and QT prolongation, in the absence of additional evidence, the simultaneous use of bedaquiline and delamanid is not recommended [52, 53].

\section{Delamanid and pretomanid}

Delamanid and pretomanid belong to the nitroimidazole class of antibiotics, presently undergoing phase II and phase III clinical trials (table 6). They inhibit the synthesis of mycolic acids, which are components of the cell envelope of M. tuberculosis. Delamanid showed, both in vitro and in vivo, a high activity (and significant early bactericidal activity (EBA)) in adult cases affected by pulmonary TB $[54,55]$. In a phase II randomised, placebo-controlled, multinational clinical trial in patients with MDR-TB, delamanid administered for 2 months at two different drug doses (100 and $200 \mathrm{mg}$ twice daily) in addition to OBR achieved a significant increase in culture conversion compared with placebo (45\% in the 100-mg group versus $42 \%$ in the $200-\mathrm{mg}$ group and $29 \%$ in the placebo group) [42]. In a subsequent open-label extension trial for MDR/XDR-TB, the mortality rates in patients receiving delamanid for at least 6 months were $1 \%$ versus $8.3 \%$, in those treated for 2 months or less [43]. Although delamanid was well tolerated, QT prolongation was more frequently reported in patients receiving delamanid against those receiving placebo [42]. Based on the available evidence, WHO recommends the use if delamanid at the dose of $100 \mathrm{mg}$ twice daily for 6 months, added to OBR in adults, when pharmacovigilance is in place and informed consent ensured [56].

A recent retrospective analysis of clinical studies carried out so far showed that the greatest reduction in mortality (around four-fold) occurred among patients treated with delamanid for $\geq 6$ months versus those treated for $\leq 2$ months [57]. Although anecdotal evidence suggests that delamanid is effective and safe in children [14], two clinical trials (www.clinicaltrials.gov identifier numbers NCT01859923 and NCT01856634) are studying delamanid in the treatment of paediatric MDR-TB.

Pretomanid (previously known as PA-824) has a low MIC for M. tuberculosis, comparable to that of isoniazid. This drug was studied as part of different potential new regimens. DiACON and co-workers [40, 41, 44, 46] assessed the 14-day early bactericidal activity of a regimen composed of pretomanid, moxifloxacin and pyrazinamide, which proved to be significantly higher than that of bedaquiline alone, bedaquiline plus pyrazinamide and bedaquiline plus pretomanid (but not to pretomanid plus pyrazinamide), and comparable to that of the standard treatment regimen (isoniazid, rifampicin and 
TABLE 6 Summary of the main new antituberculosis drugs with the most relevant studies and related findings

\begin{tabular}{|c|c|c|c|c|c|c|}
\hline Drug & Class & Study ID number & $\begin{array}{l}\text { Clinical trial } \\
\text { phase }\end{array}$ & $\begin{array}{l}\text { Registration } \\
\text { number }\end{array}$ & Main findings & [Ref.] \\
\hline Bedaquiline & Diarylquinoline & TMC207-TIDP13-C208 & $\|$ & NCT00449644 & $\begin{array}{l}\text { The addition of delamanid (TMC207) to OBR reduced the time to } \mathrm{C} \text { conversion, as } \\
\text { compared with OBR (HR } 11.8,95 \% \mathrm{Cl} 2.3-61.3 ; \mathrm{p}=0.003 \text { ) and increased the proportion } \\
\text { of C converters ( } 48 \% \text { versus } 9 \% \text { ). The mean } \log _{10} \mathrm{CFU} \text { count in SS declined more } \\
\text { rapidly in the TMC207 group than in OBR group. No significant differences in average } \\
\text { plasma TMC207 concentrations were noted between patients with and those without } \mathrm{C} \\
\text { conversion. Most AEs were mild to moderate. }\end{array}$ & [41] \\
\hline \multirow[t]{2}{*}{$\begin{array}{l}\text { Delamanid } \\
\text { (OPC 67683) }\end{array}$} & Nitroimidazole & $242-07-204$ & $\|$ & NCT00685360 & $\begin{array}{l}\text { Among patients who received OBR plus } 100 \mathrm{mg} \text { of delamanid twice daily, } 45.4 \% \text { had } \mathrm{C} \\
\text { conversion at } 2 \text { months, as compared with } 29.6 \% \text { of patients receiving OBR ( } \mathrm{O}=0.008) \text {. } \\
\text { As compared with OBR, the group receiving OBR plus delamanid } 200 \mathrm{mg} \text { twice daily } \\
\text { had a higher proportion of SS and C conversion ( } 41.9 \%, \mathrm{p}=0.04) \text {. Most AEs were mild to } \\
\text { moderate and evenly distributed across groups. Although no clinical events due to QT } \\
\text { prolongation on ECG were observed, QT prolongation was reported significantly more } \\
\text { frequently in the delamanid groups. }\end{array}$ & [42] \\
\hline & & $242-09-213$ & III & NCT01424670 & $\begin{array}{l}\text { Patients who participated in the above trial of delamanid and the subsequent open-label } \\
\text { extension trial were eligible to participate in a } 24 \text {-month observational study designed } \\
\text { to capture treatment outcomes. Favourable outcomes were observed in } 143(74.5 \%) \text { out } \\
\text { of } 192 \text { patients receiving delamanid for } \geq 6 \text { months, compared to } 126(55 \%) \text { out of } 229 \\
\text { patients who received delamanid for } \leq 2 \text { months. Mortality was reduced to } 1.0 \% \text { among } \\
\text { those receiving long-term delamanid versus short-term/no delamanid }(8.3 \% \text {; } p<0.001) \text {. } \\
\text { Treatment benefit was also seen among XDR-TB patients. }\end{array}$ & [43] \\
\hline \multirow[t]{3}{*}{$\begin{array}{l}\text { Pretomanid } \\
\text { (PA-824) }\end{array}$} & Nitroimidazole & NC-001-( J-M-Pa-Z) & $\|$ & NCT01215851 & $\begin{array}{l}\text { The 14-day EBA of PaMZ }(n=13 ; \text { mean } \pm 500.233 \pm 0.128) \text { was significantly higher than that of } \\
\text { bedaquiline }(n=14 ; 0.061 \pm 0.068) \text {, bedaquiline-pyrazinamide }(n=15 ; 0.131 \pm 0.102) \text {, } \\
\text { bedaquiline- } \mathrm{Pa}(\mathrm{n}=14 ; 0.114 \pm 0.050) \text { but not } \mathrm{PaZ}(\mathrm{n}=14 ; 0.154 \pm 0.040) \text { and comparable } \\
\text { with that of standard treatment }(n=10 ; 0.140 \pm 0.094) \text {. Treatments were well tolerated } \\
\text { and appeared safe. One patient on PaMZ was withdrawn because of corrected } Q T \\
\text { interval changes exceeding pre-specified criteria. }\end{array}$ & [44] \\
\hline & & NC-002-(M-Pa-Z) & $\|$ & NCT01498419 & $\begin{array}{l}\text { The study evaluated a novel regimen for efficacy and safety in DS-TB and MDR-TB during } \\
\text { the first } 8 \text { weeks of treatment. Smear positive DS, treatment-naïve PTB patients } \\
\text { randomised were enrolled to receive } 8 \text { weeks of M, Pa (100 mg) and Z (MPa100Z, } \\
\text { regimen } 1 \text { ) or M, Pa (200 mg) and Z (MPa200Z, regimen 2) or the current standard } \\
\text { regimen for DS-PTB (HRZE) as positive control. A group of MDR-TB participants } \\
\text { received M } 400 \mathrm{mg}, \mathrm{Pa} 200 \mathrm{mg} \text { and Z } 1500 \mathrm{mg} \text { (DRMPa200Z). The regimen } 1 \mathrm{BA} \text { days } 0- \\
56 \text { (n=54; } 0.155,95 \% \mathrm{BCl} 0.133-0.178 \text { ) in DS-TB patients was significantly greater than } \\
\text { for standard regimen (n=54; } 0.112,95 \% \mathrm{BCl} 0.093-0.131) \text {. Regimen } 2 \text { had similar BA to } \\
\text { the standard regimen. The day 7-14 BA correlated well with days 7-56. AEs were } \\
\text { equally distributed among group and control subjects. The most common AE was } \\
\text { hyperuricaemia in } 59 \text { (28.5\%) patients spread similarly across treatment groups. Other } \\
\text { common AEs were nausea in } 37 \text { (17.9\%) and vomiting in } 25 \text { (12.1\%) patients. No patient } \\
\text { had corrected QT interval exceeding } 500 \text { ms. No phenotypic resistance developed. The } \\
\text { MPaZ combination, previously found to have promising activity over } 14 \text { days in DS-TB, } \\
\text { was safe, well tolerated and demonstrated superior BA in DS-TB during } 8 \text { weeks } \\
\text { treatment. Results were consistent between DS-TB and MDR-TB. }\end{array}$ & [45] \\
\hline & & NC-003-(C-J-Pa-Z) & $\|$ & NCT01691534 & 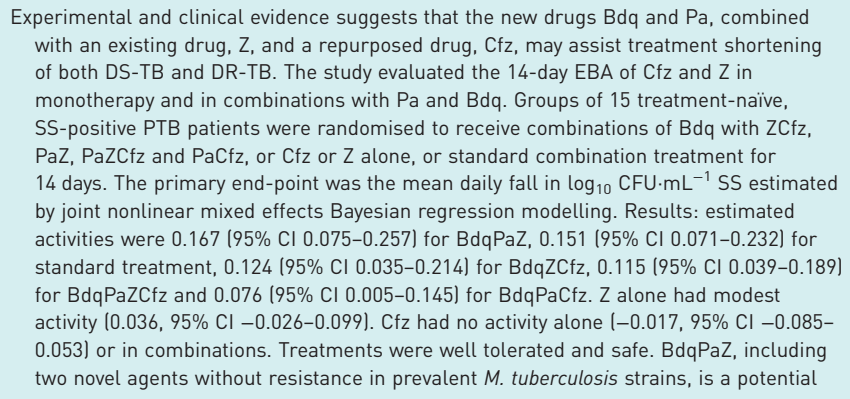 & [46] \\
\hline
\end{tabular}


TABLE 6 Continued

Class

Study ID number

Clinical trial

Registration

Main findings

\begin{tabular}{|c|c|c|c|c|c|c|}
\hline & & & & & $\begin{array}{l}\text { new TB treatment regimen. Cfz had no measurable activity in the first } 14 \text { days of } \\
\text { treatment. }\end{array}$ & \\
\hline $\begin{array}{l}\text { Sutezolid } \\
\text { (PNU-100480) }\end{array}$ & Oxazolidinone & B1171003 & ॥ & NCT01225640 & $\begin{array}{l}\text { All patients completed assigned treatments and began subsequent standard TB treatment } \\
\text { according to protocol. The } 90 \% \mathrm{Cl} \text { for bactericidal activity in sputum over the } 14 \text {-day } \\
\text { interval excluded zero for all treatments and both monitoring methods, as did those for } \\
\text { cumulative WBA. There were no treatment-related serious AEs, premature } \\
\text { discontinuations or dose reductions due to laboratory abnormalities. There was no } \\
\text { effect on the QT interval. Seven (14\%) sutezolid-treated patients had transient, } \\
\text { asymptomatic ALT elevations to } 173 \pm 34 \mathrm{U} \cdot \mathrm{L}^{-1} \text { on day } 14 \text { that subsequently normalised } \\
\text { promptly; none met Hy's criteria for serious liver injury. The mycobactericidal activity of } \\
\text { sutezolid } 600 \mathrm{mg} \text { twice daily or } 1200 \mathrm{mg} \text { once daily was readily detected in sputum and } \\
\text { blood. Both schedules were generally safe and well tolerated. }\end{array}$ & [47] \\
\hline SQ109 & Ethylenediamine & LMU-IMPH-SQ109-01 & ॥ & NCT01218217 & $\begin{array}{l}\text { Study to determine safety, tolerability, pharmacokinetics and bacteriological effect of } \\
\text { different doses of SQ109 alone and in combination with rifampicin when administered } \\
\text { over } 14 \text { days. SQ109 was safe and generally well tolerated. Mild-to-moderate } \\
\text { dose-dependent gastrointestinal complaints were the most frequent AE. No relevant QT } \\
\text { prolongation was noted. Maximum SQ109 plasma concentrations were lower than MICs. } \\
\text { Exposure to SQ109 (AUCO-24) increased by drug accumulation upon repeated } \\
\text { administration in the SQ109 monotherapy groups. Co-administration of SQ109 } 150 \mathrm{mg} \\
\text { with R resulted in decreasing SQ109 exposures from day } 1 \text { to day } 14 \text {. A higher (300 mg) } \\
\text { dose of SQ109 largely outweighed the evolving inductive effect of R. The daily fall in } \\
\log _{10} \mathrm{CFU} \cdot \mathrm{mL}^{-1} \text { of sputum } 195 \% \text { CI) was } 0.093(0.126-0.059) \text { with R, } 0.133(0.166-0.100) \\
\text { with R plus } 150 \mathrm{mg} \text { of SQ109 and } 0.089(0.121-0.057) \text { with R plus } 300 \mathrm{mg} \text { of SQ109. } \\
\text { Treatments with SQ109 alone showed no significant activity. SQ109 alone or with } \\
\text { rifampicin was safe over } 14 \text { days. Upon co-administration with R, } 300 \mathrm{mg} \text { of SQ109 } \\
\text { yielded a higher exposure than the } 150-\mathrm{mg} \text { dose. SQ109 did not appear to be active } \\
\text { alone or to enhance the activity of rifampicin during the } 14 \text { days of treatment. }\end{array}$ & [48] \\
\hline $\begin{array}{l}\text { Benzothiazinones } \\
\text { (BTZO43) }\end{array}$ & $\begin{array}{l}\text { 2-[(2S)-2-methyl- } \\
\text { 1,4-dioxa-8- } \\
\text { azaspiro[4.5]dec-8-yl]- } \\
\text { 8-nitro-6-trifluoromethyl- } \\
\text { 4H-1,3-benzothiazin- } \\
\text { 4-one/Rv3790 }\end{array}$ & $\begin{array}{l}\text { Pre-clinical } \\
\text { development } \\
\text { phases }\end{array}$ & & & $\begin{array}{l}\text { Studied the interaction profiles of BTZ043 with several anti-TB drugs or drug candidates } \\
\text { against M. tuberculosis strain } \mathrm{H} 37 \mathrm{Rv} \text {, namely, R, H, E, delamanid, Pa, M, meropenem } \\
\text { with or without clavulanate and SQ-109. No antagonism was found between BTZ043 } \\
\text { and the tested compounds, and most of the interactions were purely additive. BTZ043 } \\
\text { acts synergistically with delamanid, with a fractional inhibitory concentration index of } \\
0.5 \text {. TMC207 at a quarter of the MIC }\left(20 \mathrm{ng} \cdot \mathrm{mL}^{-1}\right) \text { used in combination with BTZ043 } \\
\text { (quarter MIC } 0.375 \mathrm{ng} \cdot \mathrm{mL}^{-1} \text { ) had a stronger bactericidal effect on M. tuberculosis than } \\
\text { delamanid alone at a concentration of } 80 \mathrm{ng} \cdot \mathrm{mL}^{-1} \text {. This synergy was not observed when } \\
\text { the combination was tested on a BTZ-resistant } \mathrm{M} \text {. tuberculosis mutant, suggesting that } \\
\text { DprE1 inhibition is the basis for the interaction. This finding excludes the possibility of } \\
\text { synergy occurring through an off-target mechanism. Hypothesis that sub-MICs of } \\
\text { BTZ043 weaken the bacterial cell wall and allow improved penetration of delamanid to } \\
\text { its target. Synergy between two new antimycobacterial compounds (delamanid and } \\
\text { BTZ043) with novel targets offers an attractive foundation for a new anti-TB regimen }\end{array}$ & [49] \\
\hline
\end{tabular}

OBR: optimised background regimen; C: culture; HR: hazard ratio; CFU: colony-forming unit; SS: sputum smear; AE: adverse event; XDR: extensively drug-resistant; TB: tuberculosis; EBA: early bactericidal activity; Pa: pretomanid; M: moxifloxacin; Z: pyrazinamide; DS: drug-susceptible; MDR: multidrug-resistant; PTB: pulmonary tuberculosis; H: isoniazid; R: rifampicin; E: ethambutol; BA: bactericidal activity; BCl: Bayesian credibility interval; Bdq: bedaquiline; Cfz: clofazimine; DR-TB: drug-resistant; WBA: whole-blood bactericidal activity; ALT: alanine transaminase; MIC: minimum inhibitory concentrations; AUC0-24: area under the curve in the first $24 \mathrm{~h}$ 
FIGURE 3 Dried blood spot for therapeutic drug monitoring. a). Blood is collected on paper strips and packed in a plastic bag with a desiccant to keep the strip dry. b). Sample can be transported via regular post or any other suitable means. c). Dried blood spot is collected from the strip, drug is extracted and concentration measured using validated method. Reproduced from [31].

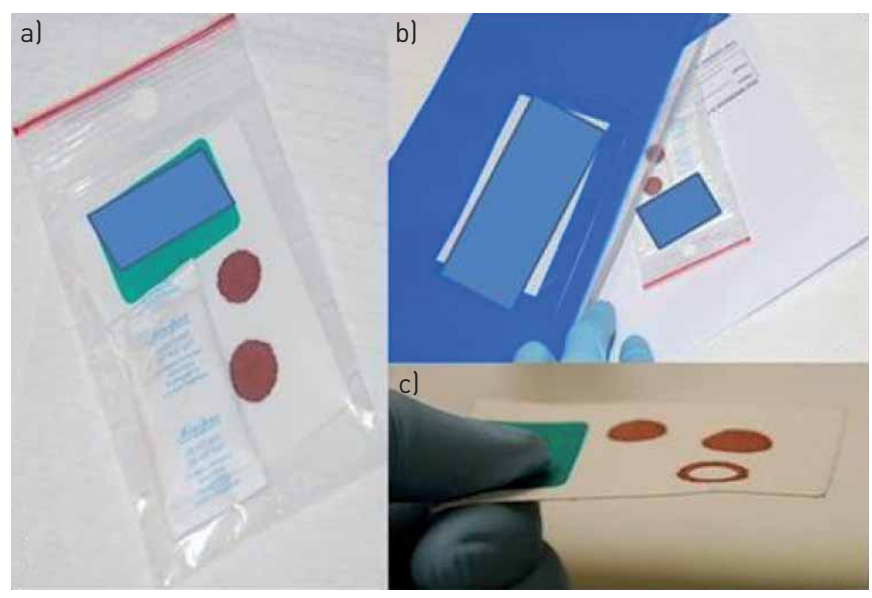

pyrazinamide with streptomycin or ethambutol). Interestingly, the addition of pyrazinamide increased the activity of both bedaquiline and pretomanid.

In a new phase IIb trial, the bactericidal activity of a new 8-week regimens including moxifloxacin, pretomanid (100 or $200 \mathrm{mg}$, according to the arm), pyrazinamide and clofazimine was compared to that of the standard anti-TB regimen to treat sputum smear positive patients with both drug-susceptible and drug-resistant TB. The new regimen yielded higher bactericidal activity than the current WHO-recommended regimen after 2 months of treatment and was well tolerated (no episode of QT interval exceeding $500 \mathrm{~ms}$ was identified) [45].

\section{Sutezolid}

Sutezolid (PNU-100480), like linezolid (see section on repurposed drugs), belongs to the oxazolidinone class of antibiotics. Their mechanism of action prevents the initiation of protein synthesis by binding to 23S RNA in the 50S ribosomal subunit of bacteria.

Having shown potent action against M. tuberculosis in the murine model [58], it was studied in phase I trials in humans, and appeared to be safe and well tolerated [59,60]. Recently, a phase II clinical trial (NCT01225640) assessing safety and efficacy using EBA and whole-blood bactericidal activity was completed (table 6) [47].

\section{SQ109}

SQ109, a 1,2-ethylenediamine, is an analogue of ethambutol. The drug is active against both drug-susceptible and drug-resistant TB by targeting MmpL3 in M. tuberculosis and specifically inhibiting the protein synthesis [61]. In vitro, it has some synergic effects with bedaquiline and favourable interactions with sutezolid. SQ109 is presently undergoing phase II clinical trials (table 6) [48].

\section{Benzothiazinones}

This new class of anti-TB drugs, in the pre-clinical development phase, are able to inhibit the synthesis of decaprenylphosphoarabinose, the precursor of the arabinans in the mycobacterial cell wall [62]. Preliminary evidence suggests that BTZ043 is potent, with activity against 240 clinical isolates of $M$. tuberculosis, including drug-susceptible, MDR-TB and XDR-TB strains. Additive interactions and no antagonism were found between BTZ043 and rifampicin, isoniazid, ethambutol, pretomanid, moxifloxacin, meropenem with or without clavulanate, and SQ109, while synergic effects were found combining BTZ043 and bedaquiline (table 6) [62].

\section{Improving the individualised approach to drug dosing: TDM}

TDM is well known among clinical pharmacologists although it is not yet very popular among TB clinicians [63-65]. Based on the collection of blood samples, it allows the evaluation ex vivo of the blood concentration of a given drug, and consequently, the potential quantitative effect on the pharmacological target. The causes leading to the development of drug resistance in M. tuberculosis are well known, and include inadequate treatment (inadequate dose or dosing frequency) [66, 67], nonadherence to the prescribed regimen and pharmacokinetic (PK) variability $[49,68]$. TDM has not yet been used to its full potential to improve therapy management when second-line anti-TB drugs are used of $[65,59]$. 
Dose adjustments are important when treating patients who are slow to respond to treatment (because of inaccurate dosing, malabsorption or altered metabolism, drug-drug interactions [64] and PK variability [49]), have MDR/XDR-TB with adverse events or are intolerant to a given drug. TDM prevents, for example, the development of further drug resistance due to exposure to drug concentrations below the MIC. When managing XDR-TB and no more than four or five effective drugs are available, TDM is potentially life-saving as it can detect malabsorption and allow dose re-adjustment. Furthermore, TDM can reduce linezolid toxicity by reducing the dose necessary $[23,31]$.

While TDM is still considered an experimental procedure, a simple and cheap dried blood spot (DBS) method allows us to take advantage of the test even from remote settings [70]. It needs only a small blood volume while allowing easy sampling, storage and transportation (fig. 3).

Some laboratories in the USA perform drug testing in-house (C.A. Peloquin, College of Pharmacy and Emerging Pathogens Institute, University of Florida, Gainesville, FL, USA; personal communication) [6]; in Europe, a proficiency testing programme is under development under the lead of the Nijmegen group in the Netherlands (C.A. Peloquin, personal communication). In the near future, a system of reference laboratories adequately covering clinical needs globally might receive the DBS by ordinary mail and rapidly send back the answer by e-mail. Although TDM is still expensive, a gradual decrease in cost is likely to occur in the future as a consequence s of an enlarged market. In addition, the reduction of the dose of drug used will pay back the TDM cost in a few days.

\section{Improving the clinical management of MDR/XDR-TB: the European Respiratory Society/WHO TB Consilium}

WHO recommends that management of MDR-TB cases is supported by a specialised team, which usually includes diverse professional perspectives (clinical, in adults and children; surgical; radiological; public health; psychological; nursing, etc.). The existence of WHO guidelines and European Standards of TB Care does not automatically guarantee appropriate treatment of MDR/XDR-TB, while rapid advice from a multidisciplinary team with clinical and management experience at national or supranational level would help to ensure proper treatment $[9,71,72]$. Similar consultation bodies dot not exist or are not used in the majority of the countries.

The European Respiratory Society (ERS), which is in the frontline of TB elimination in Europe [73-78], launched the electronic ERS/WHO TB Consilium in Vienna, Austria, in September 2012, under a Memorandum of Understanding signed with the WHO Regional Office for Europe. The overall aim of this initiative is to provide scientifically sound, evidence-based advice to national consilia and individual clinicians on how to manage drug-resistant TB and other difficult-to-treat TB cases, including co-infection with HIV and paediatric cases $[14,15,79]$, in order to prevent development of further drug resistance, and ensure monitoring and evaluation of clinical practices in the different countries (prevention, diagnosis and treatment). The platform ensures a cost-free, multilingual (English, Portuguese, Russian and Spanish), Internet-based consultation system able to provide suggestions on clinical management of complicated TB cases in less than 3 days.

In collaboration with the WHO Regional Office for Europe, a new function aimed at supporting clinicians treating trans-border migrants affected by TB has been recently launched. Furthermore, new functionality is under development (in collaboration with public organisations), aimed at allowing patients to request specific advice directly for their TB infection or disease to a physician, a nurse or a psychologist, and/or to ask for motivational support from other patients who survived, in order to support the TB elimination roadmap [73-75].

\section{The pipeline to design new regimens}

Fluoroquinolones are considered pivotal in reducing treatment duration. A recent randomised trial, however, showed a higher relapse rate of $15 \%$ and $11 \%$ in the 4 -month thrice-weekly regimens of gatifloxacin or moxifloxacin with isoniazid, rifampicin and pyrazinamide (2GHRZ3/2GHR3 or 2MHRZ3/ $2 \mathrm{MHR} 3)$, respectively, compared with $6 \%$ in the standard 6-month regimen (2EHRZ3/4HR3) during the 24 months after the end of treatment [80].

Three noninferiority trials are presently assessing the use of fluoroquinolones to shorten the treatment duration to 4 months. The OFLOTUB Trial (NCT00216385) is comparing the standard 6-month regimen with a regimen consisting of a 2-month intensive phase with gatifloxacin substituting ethambutol, followed by a 2 -month maintenance phase of gatifloxacin, isoniazid and rifampicin (2GHRZ/2GHR). Follow-up data have been obtained but the results have not yet been published [81-83]. REMox TB (NCT00864383) is comparing standard 6-month therapy with two study regimens (2 months of moxifloxacin, isoniazid, rifampicin and pyrazinamide followed by 2 months of moxifloxacin, isoniazid and rifampicin (2MHRZ/ 
2MHR) or 2 months of ethambutol, moxifloxacin, rifampicin and pyrazinamide followed by 2 months of moxifloxacin and rifampicin (2EMRZ/2MR)). RIFAQUIN (ISRCTN44153044) is comparing the standard 6-month regimen with two study regimens (2 months of daily ethambutol, moxifloxacin, rifampicin and pyrazinamide followed by 2 months of twice-weekly moxifloxacin and rifapentine (2EMRZ/2PM2) or 4 months of once-weekly moxifloxacin and rifapentine (2EMRZ/4PM1) in a maintenance phase).

The very recent study by DAWSON et al. [45] opens new perspectives on what regimens can be designed with the newly available anti-TB drugs [84]. This new phase IIb trial compared the bactericidal activity of 8-week regimens including moxifloxacin and pretomanid (100 or $200 \mathrm{mg}$, according to the arm) plus pyrazinamide against the standard anti-TB regimen to treat sputum smear positive patients with both drug-susceptible and drug-resistant TB.

The bactericidal activity of the of the 8-week regimens was higher than that of the current WHO-recommended regimen in both drug-susceptible and drug-resistant TB after 2 months of treatment. The experimental treatment was well tolerated and no episode of QT interval exceeding $500 \mathrm{~ms}$ was identified.

The study showed that rifampicin-sparing regimen might work (allowing easier and safer treatment of HIV-positive cases with protease inhibitors) while achieving rapid sputum culture conversion and reduced transmission $M$. tuberculosis with the community. Given the potential to shorten treatment duration, hopes exist to improve patient adherence.

\section{Conclusions}

In spite of the progress achieved so far, much needs still to be done to improve our approach to clinical trials of new anti-TB drugs and regimens. The surrogate markers currently adopted to measure the efficacy of a given drug are old and need complicated statistical approaches to interpolate the scientific evidence [85]. Furthermore, the time necessary to assess the pharmacological profile of a new drug is still very long and the possibility of enrolling vulnerable persons into the trials is a barrier we need to overcome soon [86]. The new WHO post-2015 End TB Strategy will support the efforts that research on new drugs and regimens requires.

\section{References}

1 World Health Organization. Global tuberculosis report 2014. WHO/HTM/TB2014.08. Geneva, World Health Organization, 2014.

2 Migliori GB, Dara M, de Colombani P, et al. Multidrug-resistant tuberculosis in Eastern Europe: still on the increase? Eur Respir J 2012; 39: 1290-1291.

3 Skrahina A, Hurevich $\mathrm{H}$, Zalutskaya A, et al. Alarming levels of drug-resistant tuberculosis in Belarus: results of a survey in Minsk. Eur Respir J 2012; 39: 1425-1431.

4 Falzon D, Gandhi N, Migliori GB, et al. Resistance to fluoroquinolones and second-line injectable drugs: impact on multidrug-resistant TB outcomes. Eur Respir J 2013; 42: 156-168.

5 Migliori GB, Sotgiu G, Gandhi NR, et al. Drug resistance beyond extensively drug-resistant tuberculosis: individual patient data meta-analysis. Eur Respir J 2013; 42: 169-179.

6 Zignol M, Dara M, Dean AS, et al. Drug-resistant tuberculosis in the WHO European Region: an analysis of surveillance data. Drug Resist Updat 2013; 16: 108-115.

7 Ulmasova DJ, Uzakova G, Tillyashayhov MN, et al. Multidrug-resistant tuberculosis in Uzbekistan: results of a nationwide survey, 2010 to 2011. Euro Surveill 2013; 18: 20609.

8 Diel R, Rutz S, Castell S, et al. Tuberculosis: cost of illness in Germany. Eur Respir J 2012; 40: 143-151.

9 Falzon D, Jaramillo E, Schünemann HJ, et al. WHO guidelines for the programmatic management of drug-resistant tuberculosis: 2011 update. Eur Respir J 2011; 38: 516-528.

10 Sotgiu G, Migliori GB. Is tuberculosis elimination a reality? Lancet Infect Dis 2014; 14: 364-365.

11 Migliori GB, Sotgiu G. Measuring the effect of tuberculosis control: a step forward. Lancet 2014; 383: 2026-2028.

12 Tanimura T, Jaramillo E, Weil D, et al. Financial burden for tuberculosis patients in low- and middle-income countries: a systematic review. Eur Respir J 2014; 43: 1763-1775.

13 Weyer K, Mirzayev F, Migliori GB, et al. Rapid molecular TB diagnosis: evidence, policy making and global implementation of Xpert MTB/RIF. Eur Respir J 2013; 42: 252-271.

14 Esposito S, D’Ambrosio L, Tadolini M, et al. ERS/WHO Tuberculosis Consilium assistance with extensively drug-resistant tuberculosis management in a child: case study of compassionate delamanid use. Eur Respir J 2014; 44: 811-815.

15 Codecasa LR, Ciconali G, Mazzola E, et al. Managing an XDR-TB outbreak: the public health face of the medal. Eur Respir J 2015; 45: 25-29.

16 Daskapan A, de Lange WCM, Akkerman OW, et al. The role of therapeutic drug monitoring in individualised drug dosage and exposure measurement in tuberculosis and HIV co-infection. Eur Respir J 2015; 45: 569-571.

17 World Health Organization. The treatment of tuberculosis: guidelines - 4th ed. Document WHO/HTM/TB/ 2009.420. Geneva, World Health Organization, 2010.

18 Albanna AS, Smith BM, Cowan D, et al. Fixed-dose combination antituberculosis therapy: a systematic review and meta-analysis. Eur Respir J 2013; 42: 721-732.

19 World Health Organization. WHO Companion handbook to the WHO guidelines for the programmatic management of drug-resistant tuberculosis. WHO/HTM/TB/2014.11. Geneva, World Health Organization, 2014. 
Dara M, Kluge H. Roadmap to prevent and combat drug-resistant tuberculosis. Copenhagen, World Health Organization Regional Office for Europe, 2011. www.euro.who.int/_data/assets/pdf_file/0014/152015/e95786.pdf Date last accessed: March 31, 2015.

21 Migliori GB, Eker B, Richardson MD, et al. A retrospective TBNET assessment of linezolid safety, tolerability and efficacy in multidrug-resistant tuberculosis. Eur Respir J 2009; 34: 387-393.

22 Cox H, Ford N. Linezolid for the treatment of complicated drug-resistant tuberculosis: a systematic review and meta-analysis. Int J Tuberc Lung Dis 2012; 16: 447-454.

23 Sotgiu G, Centis R, D'Ambrosio L, et al. Efficacy, safety and tolerability of linezolid containing regimens in treating MDR-TB and XDR-TB: systematic review and meta-analysis. Eur Respir J 2012; 40: 1430-1442.

24 Lee M, Lee J, Carroll MW, et al. Linezolid for treatment of chronic extensively drug-resistant tuberculosis. $N$ Engl J Med 2012; 367: 1508-1518.

25 Sotgiu G, Centis R, D’Ambrosio L, et al. Linezolid to treat extensively drug-resistant TB: retrospective data are confirmed by experimental evidence. Eur Respir J 2013; 42: 288-290.

26 Tang S, Yao L, Hao X, et al. Efficacy, safety and tolerability of linezolid for the treatment of XDR-TB: a study in China. Eur Respir J 2015; 45: 161-170.

27 Sotgiu G, Pontali M, Migliori GB. Linezolid to treat M/XDR-TB: available evidence and future scenarios. Eur Respir J 2015; 45: 25-29.

28 Chang KC, Yew WW, Cheung SW, et al. Can intermittent dosing optimize prolonged linezolid treatment of difficult multidrug-resistant tuberculosis? Antimicrob Agents Chemother 2013; 57: 3445-3449.

29 Bolhuis MS, Altena RV, Soolingen DV, et al. Clarithromycin increases linezolid exposure in multidrug-resistant tuberculosis patients. Eur Respir J 2013; 42: 1614-1621.

30 De Lorenzo S, Alffenaar JW, Sotgiu G, et al. Efficacy and safety of meropenem- clavulanate added to linezolid-containing regimens in the treatment of MDR/XDR-TB. Eur Respir J 2013; 41: 1386-1392.

31 Srivastava S, Peloquin CA, Sotgiu G, et al. Therapeutic drug management: is it the future of multidrug-resistant tuberculosis treatment? Eur Respir J 2013; 42: 1449-1453.

32 Engohang-Ndong J. Antimycobacterial drugs currently in Phase II clinical trials and preclinical phase for tuberculosis treatment. Expert Opin Investig Drugs 2012; 21: 1789-1800.

33 Villar M, Sotgiu G, D'Ambrosio L, et al. Linezolid safety, tolerability and efficacy to treat multidrug- and extensively drug-resistant tuberculosis. Eur Respir J 2011; 38: 730-733.

34 De Lorenzo S, Centis R, D’Ambrosio L, et al. On linezolid efficacy and tolerability. Eur Respir J 2012; 39: 770-772.

35 Sotgiu G, Lange C, Richardson MD, et al. Comment on: Daily $300 \mathrm{mg}$ dose of linezolid for the treatment of intractable multidrug-resistant and extensively drug-resistant tuberculosis. J Antimicrob Chemother 2009; 64: 879-883.

36 Sotgiu G, Centis R, D’Ambrosio L, et al. Low minimal inhibitory concentrations of linezolid against multidrug-resistant tuberculosis strains. Eur Respir J 2015; 45: 287-289.

37 Alsaad N, Wilffert B, van Altena R, et al. Potential antimicrobial agents for the treatment of multidrug-resistant tuberculosis. Eur Respir J 2014; 43: 884-897.

38 Alsaad N, van Altena R, Pranger AD, et al. Evaluation of co-trimoxazole in the treatment of multidrug-resistant tuberculosis. Eur Respir J 2013; 42: 504-512.

39 Skripconoka V, Danilovits M, Pehme L, et al. Delamanid improves outcomes and reduces mortality in multidrug-resistant tuberculosis. Eur Respir J 2013; 41: 1393-1400.

40 Diacon AH, Pym A, Grobusch MP, et al. Multidrug-resistant tuberculosis and culture conversion with bedaquiline. N Engl J Med 2014; 371: 723-732.

41 Diacon AH, Pym A, Grobusch M, et al. The diarylquinoline TMC207 for multidrug-resistant tuberculosis. $N$ Engl J Med 2009; 360: 2397-2405.

42 Gler MT, Skripconoka V, Sanchez-Garavito E, et al. Delamanid for multidrugresistant pulmonary tuberculosis. $N$ Engl J Med 2012; 366: 2151-2160.

43 Skripconoka V, Danilovits M, Pehme L, et al. Delamanid improves outcomes and reduces mortality in multidrug-resistant tuberculosis. Eur Respir J 2013; 41: 1393-1400.

44 Diacon AH, Dawson R, von Groote-Bidlingmaier F, et al. 14-day bactericidal activity of PA-824, bedaquiline, pyrazinamide, and moxifloxacin combinations: a randomised trial. Lancet 2012; 380: 986-993.

45 Dawson R, Diacon AH, Everitt D, et al. The anti-tuberculosis activity of the combination of moxifloxacin, pretomanid (PA-824) and pyrazinamide during the first eight weeks of therapy: a Phase $2 \mathrm{~b}$ open label, partially randomized trial of efficacy, tolerability and safety in patients with drug-susceptible and drug-resistant pulmonary tuberculosis. Lancet 2015 [In press DOI: 10.1016/S0140-6736(14)62002-X]

46 Diacon AH, Dawson R, von Groote-Bidlingmaier F, et al. Bactericidal activity of pyrazinamide and clofazimine alone and in combinations with pretomanid and bedaquiline. Am J Respir Crit Care Med 2015 [In press DOI: 10.1164/rccm.201410-1801OC].

47 Wallis RS, Dawson R, Friedrich SO, et al. Mycobactericidal activity of sutezolid (PNU-100480) in sputum (EBA) and blood (WBA) of patients with pulmonary tuberculosis. PLoS One 2014; 9: e94462.

48 Heinrich N, Dawson R, du Bois J, et al. Early phase evaluation of SQ109 alone and in combination with rifampicin in pulmonary TB patients. J Antimicrob Chemother 2015 [In press DOI: 10.1093/jac/dku553]

49 Srivastava S, Pasipanodya JG, Meek C, et al. Multidrug-resistant tuberculosis not due to noncompliance but to between-patient pharmacokinetic variability. J Infect Dis 2011; 204: 1951-1959.

50 Andries K, Verhasselt P, Guillemont J, et al. A diarylquinoline drug active on the ATP synthase of Mycobacterium tuberculosis. Science 2005; 307: 223-227.

51 Diacon AH, Donald PR, Pym A, et al. Randomized pilot trial of eight weeks of bedaquiline (TMC207) treatment for multidrug-resistant tuberculosis: longterm outcome, tolerability, and effect on emergence of drug resistance. Antimicrob Agents Chemother 2012; 56: 3271-3276.

52 World Health Organization. The use of bedaquiline in the treatment of multidrug- resistant tuberculosis: interim policy guidance. Document WHO/HTM/TB/2013.6. Geneva, World Health Organization, 2013.

53 Mase S, Chorba T, Lobue P, et al. Provisional CDC guidelines for the use and safety monitoring of bedaquiline fumarate (Sirturo) for the treatment of multidrug-resistant tuberculosis. MMWR Recomm Rep 2013; 62: 1-12. 
54 Matsumoto M, Hashizume H, Tomishige T, et al. OPC-67683, a nitro-dihydroimidazooxazole derivative with promising action against tuberculosis in vitro and in mice. PLoS Med 2006; 3: e466.

55 Diacon AH, Dawson R, Hanekom M, et al. Early bactericidal activity of delamanid (OPC-67683) in smear-positive pulmonary tuberculosis patients. Int J Tuberc Lung Dis 2011; 15: 949-954.

56 World Health Organization. The use of delamanid in the treatment of multidrug-resistant tuberculosis. Interim policy guidance. Document WHO/HTM/TB2014.23. Geneva, World Health Organization, 2014.

57 Wells CD, Gupta R, Hittel N, et al. Long-term mortality assessment of multidrug-resistant tuberculosis patients treated with delamanid. Eur Respir J 2015 [In press DOI: 10.1183/09031936.00176314].

58 Williams KN, Stover CK, Zhu T, et al. Promising antituberculosis activity of the oxazolidinone PNU-100480 relative to that of linezolid in a murine model. Antimicrob Agents Chemother 2009; 53: 1314-1319.

59 Wallis RS, Jakubiec WM, Kumar V, et al. Pharmacokinetics and whole-blood bactericidal activity against Mycobacterium tuberculosis of single doses of PNU-100480 in healthy volunteers. J Infect Dis 2010; 202: 745-751.

60 Wallis RS, Jakubiec W, Kumar V, et al. Biomarker-assisted dose selection for safety and efficacy in early development of PNU-100480 for tuberculosis. Antimicrob Agents Chemother 2011; 55: 567-574.

61 Sacksteder KA, Protopopova M, Barry CEIII, et al. Discovery and development of SQ109: a new antitubercular drug with a novel mechanism of action. Future Microbiol 2012; 7: 823-837.

62 Lechartier B, Hartkoorn RC, Cole ST. In vitro combination studies of benzothiazinone lead compound BTZ043 against Mycobacterium tuberculosis. Antimicrob Agents Chemother 2012; 56: 5790-5793.

63 Heysell SK, Moore JL, Keller SJ, et al. Therapeutic drug monitoring for slow response to tuberculosis treatment in a state control program, Virginia, USA. Emerging Infect Dis 2010; 16: 1546-1553.

64 Peloquin CA. Pharmacological issues in the treatment of tuberculosis. Ann NY Acad Sci 2001; 953: 157-164.

65 Peloquin CA. Therapeutic drug monitoring in the treatment of tuberculosis. Drugs 2002; 62: 2169-2183.

66 Migliori GB, Sotgiu G, D'Ambrosio L, et al. TB and MDR/XDR-TB in European Union and European Economic Area countries: managed or mismanaged? Eur Respir J 2012; 39: 619-625.

67 Raviglione MC, Lange C, Migliori GB. Preventing and managing antimicrobial resistance: imperative for chest physicians. Eur Respir J 2011; 37: 978-981.

68 Van der Werf MJ, Langendam MW, Huitric E, et al. Multidrug resistance after inappropriate tuberculosis treatment: a meta-analysis. Eur Respir J 2012; 39: 1511-1519.

69 Tortoli E, Russo C, Piersimoni C, et al. Clinical validation of Xpert MTB/RIF for the diagnosis of extrapulmonary tuberculosis. Eur Respir J 2012; 40: 442-447.

$70 \mathrm{Vu} \mathrm{DH}$, Alffenaar JWC, Edelbroek PM, et al. Dried blood spots: a new tool for tuberculosis treatment optimization. Curr Pharm Des 2011; 17: 2931-2939.

71 Migliori GB, Zellweger JP, Abubakar I, et al. European Union Standards for Tuberculosis Care. Eur Respir J 2012; 39: 807-819.

72 van der Werf MJ, Sandgren A, D'Ambrosio L, et al. The European Union standards for tuberculosis care: do they need an update? Eur Respir J 2014; 43: 933-942.

73 World Health Organization. Framework for tuberculosis elimination in low-incidence countries. Document WHO/HTM/TB/2014.13. Geneva, World Health Organization, 2014.

74 Diel R, Loddenkemper R, Zellweger JP, et al. Old ideas to innovate tuberculosis control: preventive treatment to achieve elimination. Eur Respir J 2013; 42: 785-801.

75 D’Ambrosio L, Dara M, Tadolini M, et al. TB Elimination: theory and practice in Europe. Eur Respir J 2014; 43 $1410-1420$.

76 Voniatis C, Migliori GB, Voniatis M, et al. Tuberculosis elimination: dream or reality? The case of Cyprus. Eur Respir J 2014; 44: 543-546.

77 Blasi F, Barnes PJ, Gaga M, et al. Future directions for the ERS: presidential plans. Eur Respir J 2013; 42: 875-880.

78 Blasi F, Reichman LB, Migliori GB. Presenting the European Forum for TB Innovation: innovative thinking in progressing towards TB elimination in Europe. Eur Respir J 2012; 40: 806-808.

79 D'Ambrosio L, Tadolini M, Dupasquier S, et al. ERS/WHO TB consilium: reporting on initial 10 cases. Eur Respir J 2014; 43: 286-289.

80 Jawahar MS, Banurekha VV, Paramasivan CN, et al. Randomized clinical trial of thrice-weekly 4-month moxifloxacin or gatifloxacin containing regimens in the treatment of new sputum positive pulmonary tuberculosis patients. PLoS One 2013; 8: e67030.

81 Merle CS, Fielding K, Sow OB, et al. A four-month gatifloxacin-containing regimen for treating tuberculosis. $N$ Engl J Med 2014; 371: 1588-1598.

82 Merle CS, Sismanidis C, Sow OB, et al. A pivotal registration phase III, multicenter, randomized tuberculosis controlled trial: design issues and lessons learnt from the Gatifloxacin for TB (OFLOTUB) project. Trials 2012; 13: 61.

83 Smythe W, Merle CS, Rustomjee R, et al. Evaluation of initial and steady-state gatifloxacin pharmacokinetics and dose in pulmonary tuberculosis patients by using Monte Carlo simulations. Antimicrob Agents Chemother 2013; 57: 4164-4171.

84 Sotgiu G, Migliori GB. New effective antituberculosis regimens. Lancet 2015 [In press DOI: 10.1016/S0140-6736 (14)62303-5].

85 Kurbatova EV, Cegielski JP, Lienhardt C, et al. Sputum culture conversion as a prognostic marker for end-of-treatment outcome in patients with multidrug-resistant tuberculosis: a secondary analysis of data from two observational cohort studies. Lancet Respir Med 2015; 3: 201-209.

86 Zumla AI, Schito M, Maeurer M. Advancing the portfolio of tuberculosis diagnostics, drugs, biomarkers, and vaccines. Lancet Infect Dis 2014; 14: 7-9. 